This item was submitted to Loughborough's Research Repository by the author.

Items in Figshare are protected by copyright, with all rights reserved, unless otherwise indicated.

\title{
Governance pressures and performance outcomes of sustainable supply chain management - An empirical analysis of UK manufacturing industry
}

\section{PLEASE CITE THE PUBLISHED VERSION}

https://doi.org/10.1016/j.jclepro.2016.07.098

\section{PUBLISHER}

(C) Elsevier

VERSION

AM (Accepted Manuscript)

\section{PUBLISHER STATEMENT}

This work is made available according to the conditions of the Creative Commons Attribution-NonCommercialNoDerivatives 4.0 International (CC BY-NC-ND 4.0) licence. Full details of this licence are available at: https://creativecommons.org/licenses/by-nc-nd/4.0/

\section{LICENCE}

CC BY-NC-ND 4.0

\section{REPOSITORY RECORD}

Esfahbodi, Ali, Yufeng Zhang, Glyn Watson, and Tao Zhang. 2019. "Governance Pressures and Performance Outcomes of Sustainable Supply Chain Management - an Empirical Analysis of UK Manufacturing Industry". figshare. https://hdl.handle.net/2134/37971. 


\section{Title page with author details}

Special Volume on "Making, Buying and Collaborating for More Sustainable Production and Consumption"

"Governance Pressures and Performance Outcomes of Sustainable Supply Chain Management - An Empirical Analysis of UK Manufacturing Industry"

\section{Corresponding author:}

Name: Ali Esfahbodi

Email: axe901@bham.ac.uk

Tel: +447552114421

Affiliation: The University of Birmingham, Birmingham Business School

Address: University House, Edgbaston Park Road, Edgbaston, Birmingham B15 2TT, UK.

\section{Co-author:}

Name: Yufeng Zhang

Email: zhangys@bham.ac.uk

Affiliation: The University of Birmingham, Birmingham Business School

Position: Director of Business Programmes with Engineering

\section{Co-author:}

Name: Glyn Watson

Email: g.r.watson@bham.ac.uk

Affiliation: The University of Birmingham, Birmingham Business School

Position: Deputy Head of College, College of Social Sciences

\section{Co-author:}

Name: Tao Zhang

Email: t.zhang.1@bham.ac.uk

Affiliation: The University of Birmingham, Birmingham Business School

Position: Director of Marketing PhD Programme 


\title{
Governance Pressures and Performance Outcomes of Sustainable Supply Chain Management - An Empirical Analysis of UK Manufacturing Industry
}

\begin{abstract}
Although sustainable supply chain management (SSCM) has recently received increasing attention among UK manufacturing firms, there is a concern as to whether SSCM practices are being implemented because they are profitable or only because of governance coercive pressure. Thus, the aims of this paper are twofold: first, determining the role of governance in the adoption of SSCM practices; second, investigating whether SSCM practices can be both environmentally beneficial and commercially viable. In light of these issues, this paper develops and empirically assesses an integrated model of governance pressures-SSCM practices-performance. Data was collected from $146 \mathrm{UK}$ manufacturing managers, and analysed using the structural equation modelling method. Exogenous driving forces of governance were found to be precursors to the successful implementation of SSCM practices. The empirical results further suggest that while the implementation of sustainable supply chain management has a positive effect on environmental performance, it does not necessarily lead to improved economic performance, as only sustainable procurement was found to have a positive effect on economic performance. This paper contributes to the literature by highlighting the role of governance in SSCM adoption and performance gains in environmental protection while economic performance is partially compromised. The results also provide useful insights for both managers seeking to adopt sustainable practices and policy-makers seeking to further promote sustainable supply chain.
\end{abstract}

Keywords: Sustainable supply chain management (SSCM); Coercive pressure; Manufacturing firms; Environmental performance; Economic performance; Structural Equation Modelling (SEM); UK. 


\section{Introduction}

There are increasing stakeholder expectations for firms to be fully responsible for their business operations and to clearly demonstrate their environmental and ethical behaviour (Lozano, 2008). Such expectations, along with growing institutional pressures, have caused manufacturing firms to adjust their traditional supply chains to incorporate sustainable inputs in order to provide more sustainable products, services and product-service combinations (Vezzoli et al., 2012). In response to these pressures, a growing number of manufacturing firms have begun to undertake environmental initiatives across their supply chains and to implement sustainable supply chain management (SSCM) practices (Su et al., 2015). While a variety of institutional pressures (governance pressure in particular) are major motivating forces that lead firms to pursue SSCM practices (Zhu et al., 2013), a number of debates have recently opened up to question whether the governance pressure can actually drive the adoption of SSCM practices further (Sarkis et al., 2010; Boström et al., 2015).

Environmental concerns and the inclusion of sustainable practices within the context of the supply chain are a subject that has become popular in both academia and industry, with the hope of mitigating environmental damage while achieving financial performance gains (Lozano et al., 2015). As institutional pressures push firms to adopt and maintain environmental initiatives and produce environmentally friendly products and services, firms must consider the impact of the adoption of such environmental initiatives on both their environmental performance and their business performance (Gimenez et al., 2012). The recognition of financial benefits gained from environmental initiatives in firms' bottom line is crucial for the adoption of such environmental initiatives. This contention is grounded on the fact that the economic performance has traditionally been, and continues to be, the key priority for firms (Zhu and Sarkis, 2007).

While previous studies have attempted to link SSCM practices with organisational performance (Zhu and Sarkis, 2004; Rao and Holt, 2005), they have neglected to include the driving role of governance as a key antecedent to the adoption of such environmental initiatives. We argue that the existence of and response to governance pressures will influence the relationships between SSCM practices and performance outcomes. In that sense, such governance pressures have a causal impact on SSCM adoption, which in turn influences the relationship between SSCM practices and organisational performance, particularly from a holistic and integrated perspective (Green et al., 2010a). Therefore, we 
should consider the effects of governance pressures when examining the relationship between the adoption of SSCM practices and performance outcomes. Currently in supply chain management literature there is a dearth of studies empirically examining the relationship between adopting SSCM practices and performance outcomes considering the effects of governance pressures from a holistic and integrated perspective. Moreover, there is a level of ambiguity within the existing knowledge concerning the merits of undertaking an SSCM agenda- whether it can deliver both environmental improvements and economic benefits (Zhu and Sarkis, 2007; Seuring and Müller, 2008a). The existing research provides some direction but remains inconclusive as they are of contradiction with one another (Zhu et al., 2005; Green et al., 2012a).

In order to bridge the knowledge gap in the literature and advance the contemporary understanding of SSCM, this research seeks to investigate an integrated Governance Pressures $\rightarrow$ SSCM Practices $\rightarrow$ Performance Outcomes relationships. This paper serves two purposes: (1) determining the role of governance in the adoption of SSCM practices; (2) investigating the consequences of governance within sustainable supply chains in terms of performance outcomes. We utilise the institutional theory lens to help explain the exogenous driving force of governance in the adoption of SSCM practices and their related influence on performance outcomes.

The remainder of this paper is organised as follows. A literature review and theoretical foundation are presented in Section 2, addressing SSCM drivers (i.e. governance pressures), practices and performance. Section 3 presents the research method along with a summary of the samples and data. Section 4 presents the analysis of the data and reports the results of this study, followed by a discussion of the key findings in Section 5. Section 6 concludes the paper.

\section{Theoretical development and hypotheses}

Firms involved in today's sophisticated supply chains face increasing pressure from various stakeholders, especially governments, to accept responsibility for social and environmental matters beyond their immediate organisational boundaries (Boström et al., 2015). These regulatory pressures lead firms to pay close attention to their commensurate environmental alignment in an SCM context in particular. Several organisational theories including resource dependence, transaction cost economics and institutional theory have been used to understand 
how firms adopt and undertake environmental initiatives across their supply chains (Sarkis et al., 2011; Niesten and Jolink, 2014; Lozano et al., 2015). Using the theoretical anchors of the institutional theory, we argue that firms adopt SSCM practices in response to intuitional pressures mainly exerted by governance.

\subsection{Governance pressures and SSCM practices: an institutional perspective}

From an institutional perspective, firms' responsiveness to the adoption of new organisational practices such as environmental initiatives may be influenced by three institutional isomorphic pressures: normative, mimetic, and coercive pressures (DiMaggio and Powell, 1983; Sarkis et al., 2011). In essence the aforementioned institutional pressures can influence a firm's environmental alignment. Several studies show how firms have been driven by institutional norms to enhance environmental performance by adopting proactive environmental programmes such as SSCM practices (Zhu et al., 2007; Sarkis et al., 2010). Among institutional pressures, coercive pressure, which refers to the conformity occurring through influence exerted by those in power, is the most important factor that drives environmental initiatives among manufacturing firms (Zailani et al., 2012). From a practical perspective, government agencies as powerful groups can influence the actions of an organisation by enacting environmental regulations (Rivera, 2004). In this paper, governance pressure is referred to as coercive pressure in the form of environmental regulations that drive the implementation of SSCM practices.

Scarcity of resources and environmental degradation have prompted governmental organisations, at both national and international level, to exert pressures on manufacturers, the main resource consumers and polluters, through increasing environmental regulatory and tax policies (Taylor and Taylor, 2013; Yu and Ramanathan, 2015). For example, the European Union has enacted various Environmental Directives such as Waste Electrical and Electronic Equipment (WEEE), Energy-using Products (EuP), Restriction of Hazardous Substances (RoHS), End of Life Vehicle (ELV), and so forth, which lead manufacturers to minimise negative environmental impact (Gerrard and Kandlikar, 2007; Koh et al., 2012). Such international regulatory policies not only push the EU manufacturers to undertake environmental initiatives across their supply chains, but also force the manufacturers in developing countries which intend to export and sell to Europe to embark upon the adoption of SSCM practices (Seuring et al., 2008; Sarkis et al., 2010). 
Therefore, while all institutional pressures can be valid motivators for the adoption of environmental practices, coercive pressures exerted from government agencies and national or international regulators are deemed to be the major driving forces that influence the adoption of SSCM practices (Lai et al., 2011; Lin and Ho, 2011; Zailani et al., 2012). Thus, we argue that governance pressures are the main driving forces in the adoption of SSCM practices. With this set of arguments, we hypothesise:

H1: Governance pressures are directly and positively associated with the adoption of SSCM practices

It is worth mentioning that other possible antecedents to the implementation of SSCM practices exist that may contribute to a firm's decision to adopt sustainable practices in addition to governance pressures such as market orientation (Green et al., 2015). However, this was not feasible within the scope of this paper, other external antecedents to the implementation of SSCM practices deserves future research.

\subsection{SSCM practices}

In essence, a traditional supply chain is a set of business actions that directly involves the upstream or downstream flows of information, products and services from a point-of-origin to a point-of-consumption (Lambert et al., 1998). Unlike the traditional supply chain, the sustainable supply chain considers the environmental impacts of the production process as goods flow through the supply chain (Hsu and Hu, 2009; Seuring and Müller, 2008b). Hence, a sustainable supply chain extends:

[...] the traditional supply chain to include activities that aim at minimizing environmental impacts of a product throughout its entire life cycle, such as green design, resource saving, harmful material reduction, and product recycle (Beamon, 1999, p.332)

Sustainable supply chain management (SSCM) simply integrates environmental concerns into supply chain management (Linton et al., 2007). The literature in SSCM has been growing as both practitioners and researchers begin to realise that the management of environmental programmes and operations do not end at the boundaries of the organisation (Jolink and Niesten, 2015; Su et al., 2015). Organisations may undertake a set of SSCM initiatives to minimise the negative environmental impacts associated with the entire lifecycle of its products or services, starting from design through the acquisition of raw materials to consumption and product disposal (Zsidisin and Siferd, 2001; de Bakker et al., 2002). 
The concept of SSCM has evolved to include boundary-spanning activities such as sustainable procurement (Carter and Carter, 1998), eco-design (Seuring and Müller, 2008b), sustainable distribution (Vachon and Klassen, 2006b), and investment recovery (Zhu and Sarkis 2006; Zhu et al., 2007). Given the multi-dimensional expansion of SSCM literature, our study focuses on four major SSCM practices: sustainable production, sustainable design, sustainable distribution and investment recovery. These four areas represent the major implementation of SSCM practices, as they encompass the main internal and external activities and functions within sustainable supply chain management (Zhu et al., 2005; Su et al., 2015). Therefore, governance pressures as the main driving forces in the adoption of SSCM practices now can be linked to each of the four major SSCM practices in the form of coercive pressures encompassing environmental regulations. As previously discussed, we define environmental regulations as the coercive pressures driving the implementation of SSCM practices. In light of this, we break down our primary hypothesis into four subhypotheses and propose the following:

Hla. Coercive pressures are directly and positively associated with sustainable procurement. $H 1 b$. Coercive pressures are directly and positively associated with sustainable distribution. H1c. Coercive pressures are directly and positively associated with sustainable design. HId. Coercive pressures are directly and positively associated with investment recovery.

\subsection{SSCM practices and performance outcomes}

Previous research has explored the relationships between the adoption of SSCM practices and performance outcomes, including environmental, operational and economic performance (Zhu and Sarkis, 2007; Green et al., 2012a; Yu and Ramanathan, 2015). Porter and Van der Linde (1995) contributed to the environment-competiveness related relationships by developing a paradigm of balancing a society's desire for environmental protection with the economic burden on industry. They advanced the idea that environmental regulations through coercive pressure can generate better economic outcomes in terms of innovation. However, recent emergent studies have started to throw doubt on this issue, questioning the stance of previous literature concerning the positive impacts of SSCM practices on performance outcomes (Zhu et al., 2013). Hence, the contemporary knowledge of SSCM has been mixed on the relationships between environmental and economic performance and adoption of SSCM practices, reporting inconclusive findings (Geffen and Rothenberg, 2000; Rao and Holt, 2005; Zhu et al., 2010). These uncertainties and ambiguities within the existing knowledge in this area necessitate further empirical investigation. 


\subsubsection{Relationships between SSCM practices and environmental performance}

Although early studies found little relationship between environmental practice and environmental performance (e.g. Levy, 1995), in most cases the literature demonstrates that SSCM practices can improve environmental performance (Rao, 2005; Vachon and Klassen, 2006a; Zhu et al., 2007). Particularly, recent studies tend to agree on a positive relationship between sustainable supply chain management and environmental performance (Hollos et al., 2012; Taylor and Taylor, 2013). Some prominent research has offered insights into the potential patterns of supply-chain-based relations for improving environmental performance (Zhu et al., 2012; Lee et al., 2012). For example, Lee et al. (2012) suggested that interorganisational linkage and collaboration with suppliers aid the adoption and development of innovative environmental technologies and bring environmental improvement. Tsoulfas and Pappis (2006) also asserted that the interaction of customer and supplier staff, partnership agreements and joint research and development lead to improvements in environmental performance. Hence, we argue that there is consensus within the literature that the implementation of SSCM practices results in relatively improved environmental performance.

In essence, the four major SSCM practices of sustainable procurement, sustainable design, sustainable distribution, and investment recovery are environmental-friendly initiatives in nature. These initiatives are designed to minimise a product's environmental impact without creating a negative trade-off with other performance dimensions, such as costs and functionality (Zhu et al., 2005; Green et al., 2012a). This is also in line with Porter and Van der Linde's (1995) argument for a balance between a society's desire for environmental protection and the economic burden on industry. The implementation of each individual SSCM practice is deemed to have direct environmental results as measured by reductions in air emissions, effluent waste, solid waste, and the consumption of toxic materials (Zhu and Sarkis, 2004; Seuring and Müller, 2008b). Therefore, the implementation of sustainable procurement, sustainable design, sustainable distribution, and investment recovery is expected to result in improved environmental performance due to their capability in reduction of material consumptions, wastes, emissions, energy usage, and excessive inventory (Zhu and Sarkis, 2007; Seuring and Müller, 2008a). Accordingly, we propose that: 
H2a. Sustainable procurement is directly and positively associated with environmental performance.

H2b. Sustainable distribution is directly and positively associated with environmental performance.

H2c. Sustainable design is directly and positively associated with environmental performance.

H2d. Investment recovery is directly and positively associated with environmental performance.

\subsubsection{Relationships between SSCM practices and economic performance}

In essence, SSCM practices mainly focus on the elimination of wastes associated with material acquisitions, product design, delivery and disposal (Vachon and Klassen, 2006a; Seuring et al., 2008). Such waste minimisation should lead to reduced costs, resulting in improved economic performance. Whether SSCM practices are positively or negatively related to economic performance is still an open question (Vachon and Klassen, 2006b; Green et al., 2012a; Hollos et al., 2012). Some studies have shown that environmental management programmes such as SSCM practices have a positive relationship with an organisation's economic performance (Rao and Holt 2005). Such environmental management practices can improve corporate reputation and customer satisfaction, which can in turn bring improved economic performance (Tang et al., 2012). In general, inter-firm linkage provides formal and informal mechanisms that promote trust, reduce risk and in turn increase cooperation, commitment, and hence profitability (Zhu et al., 2012). Furthermore, Seuring and Müller (2008b) and Sarkis et al. (2010) argued that the success in addressing environmental issues may provide new opportunities for competition and new ways to add value to core business programmes. However, some other researchers have stated that economic performance is not reaped in short-term profitability and sales performance with the implementation of SSCM practices (Bowen et al. 2001).

In fact, the literature over the past two decades is still not clear whether benefits or costs dominate when adopting SSCM practices (Seuring and Müller, 2008a). The reasons for the variation in these findings may be due to the heterogeneity of the types of environmental management practices adopted by the firm and industry (Zhu et al., 2005). Given the strength of the overall literature in supporting improved economic performance when SSCM practices are implemented, we postulate the following hypotheses.

H3a. Sustainable procurement is directly and positively associated with economic performance 
H3b. Sustainable distribution is directly and positively associated with economic performance.

H3c. Sustainable design is directly and positively associated with economic performance. $H 3 d$. Investment recovery is directly and positively associated with economic performance.

\subsubsection{Relationship between environmental and economic performance}

As the measurement scales of the environmental and economic performance are constructed, economic performance reflects savings that result from improved environmental performance (Zhu and Sarkis, 2006). The cost saving nature of environmental performance should lead to improved economic performance, sustaining decreases in the associated costs (Green et al., 2012a). Therefore, an additional hypothesis linking environmental performance with economic performance is proposed:

H4. Environmental performance is directly and positively associated with economic performance.

\subsection{Theoretical model}

The theoretical model is a path analytical model with six latent variables (see Fig. 1): Coercive pressures, sustainable procurement, sustainable distribution sustainable design, investment recovery, environmental performance and economic performance. Each of the hypotheses depicted in our research model is theorised as being direct and positive. Generally, SSCM practices are the focal constructs in the theorised model, with governance pressures as antecedents and environmental and economic performance as consequences. In addition, governance pressures in the form of environmental regulations drive the adoption of SSCM practices including sustainable procurement, sustainable distribution, sustainable design, and investment recovery (Zhu et al., 2013). Changes made as a result of governance pressures impact the adoption of SSCM practices, which will impact both environmental and economic performance. Fig. 1 outlines the theoretical model that guides this research. 


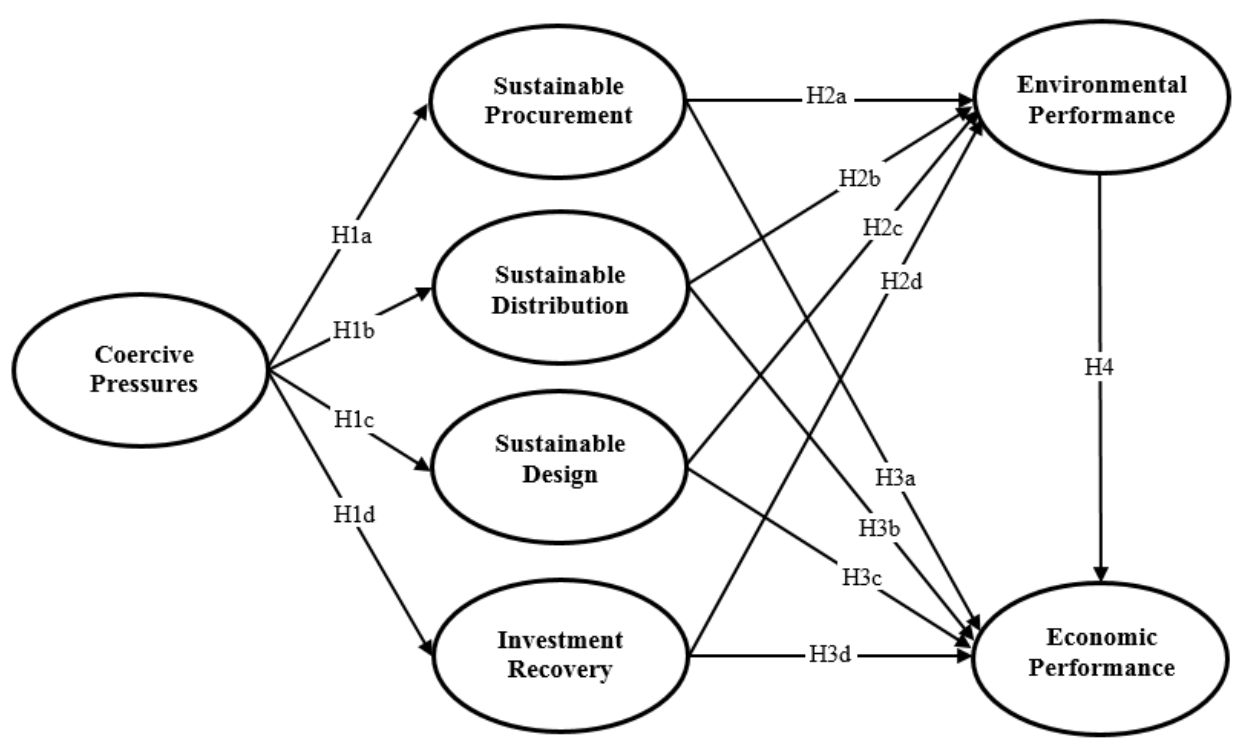

Fig. 1. Governance pressures-SSCM practices-performance model with hypotheses

The relationships between governance pressures, implementation of SSCM practices and environmental and economic performance are theorised in order to first investigate whether the exogenous driving force of governance exists in the adoption of SSCM practices and understand if it is necessary and sufficient; and second to assess the impact of such SSCM implementation, which has inwardly included the effects of the governance-based antecedents, on performance outcomes. Definitions of the constructs incorporated in the model are provided in Table 1.

Table 1 Construct definitions

\begin{tabular}{cl}
\hline \multicolumn{1}{c}{ Construct } & \multicolumn{1}{c}{ Definition } \\
\hline Coercive pressures & $\begin{array}{l}\text { Pressures exerted from governance in the form of environmental regulations and } \\
\text { legislations which enhance a firm's environmental alignment (Zhu et al., 2013) }\end{array}$ \\
\hline Sustainable Procurement & $\begin{array}{l}\text { Sustainable procurement focuses on cooperating with suppliers for the purpose of } \\
\text { developing products that are environmentally sustainable (Carter and Carter, 1998; } \\
\text { Zhu and Sarkis, 2006) }\end{array}$ \\
\hline Sustainable Distribution & $\begin{array}{l}\text { Sustainable distribution refers to any means of transportation of products or } \\
\text { services from suppliers to manufacturers to final customers with the purpose of } \\
\text { having the least possible negative environmental impact (Zhu and Sarkis, 2006; } \\
\text { Esty and Winston, 2009; Green et al., 2012b) }\end{array}$ \\
\hline Sustainable Design & $\begin{array}{l}\text { Sustainable design requires that manufacturers design products that minimise } \\
\text { consumption of materials and energy, facilitate the reuse, recycling and recovery of } \\
\text { component materials and parts, and avoid or reduce the use of hazardous products } \\
\text { within the manufacturing process (Zhu and Sarkis, 2006) }\end{array}$ \\
\hline $\begin{array}{c}\text { Investment Recovery } \\
\text { Investment recovery refers to the process of recovering the value of unused or end } \\
\text { of life assets through effective reuse or surplus sales. It requires the sale of excess } \\
\text { Performance }\end{array}$ & $\begin{array}{l}\text { Environmental performance relates to the ability of manufacturing plants to reduce } \\
\text { air emissions, effluent waste and solid wastes and the ability to decrease } \\
\text { consumption of hazardous and toxic materials (Zhu and Sarkis, 2006) }\end{array}$ \\
\hline Economic Performance & $\begin{array}{l}\text { Economic performance relates to the manufacturing plant's ability to reduce costs } \\
\text { associated with purchased materials, energy consumption, waste treatment, waste } \\
\text { discharge and fines for environmental accidents (Zhu and Sarkis, 2006) }\end{array}$ \\
\hline
\end{tabular}




\section{Method}

\subsection{Measures}

The measures of coercive pressures, SSCM practices and performance components are developed on the basis of previous studies (e.g. Zhu and Sarkis, 2006; Sarkis et al., 2010). Zhu et al. (2013) developed the measuring components of coercive pressures with reference to the isomorphic forces within institutional theory mainly associated with coercive forces (DiMaggio and Powell, 1983). We adopt Zhu et al.'s (2013) measurement items for the coercive pressures construct. Furthermore, Zhu and Sarkis (2006) developed and tested a measurement model for SSCM practice implementation and performance outcomes. They found four underlying constructs which reflect the dimensions of SSCM practices and performance measures, including economic, operational and environmental performance. In this paper, we select two dimensions, i.e. environmental performance and economic performance. We adopt the measurement items of Zhu and Sarkis (2006) for the "sustainable procurement" and "investment recovery" constructs. For "sustainable distribution" and "sustainable design", we utilise additional items found in Esty and Winston (2009) and Green et al. (2012b).

The measurement items for evaluating coercive pressures, SSCM practices and performance outcomes are summarised in the Appendix A. These measurement items have been operationalised in a survey questionnaire to evaluate performance outcomes as a result of SSCM practice implementation driven by governance pressures. Respondents were asked to evaluate the importance of each coercive pressure on the adoption of SSCM practices, using a five-point Likert scale ranging from $1=$ unimportant to $5=$ very important. In addition, a five-point interval scale for evaluating individual SSCM practice items was provided, ranging from 1 = no implementation to 5 = implemented fully. Respondents were further asked to evaluate the significance level of performance improvement due to SSCM practices with a five-point scale ranging from $1=$ not at all to $5=$ significant. To avoid confusing respondents with three different five-point Likert scales, we provided a brief explanation of the three groups of items at the beginning of each survey section. 


\subsection{Sampling}

Given the fact that resource consumption, waste production and implementation of environmental management practices are mostly associated with manufacturing, our survey focused on manufacturers, particularly those in the chemical, electronic, automotive and mechanical engineering sectors. The manufacturing firms in these sectors are the main polluters and resource consumers. These manufacturers have been traditionally associated with higher-than-average resource consumption, waste generation and implementation of environmental management practices (Zhu et al., 2013). Considering this manufacturing focus, data was collected from a sample of manufacturing managers working for the UK manufacturers. The UK was chosen as the empirical setting for this study because of the regional importance of British manufacturers in terms of their share of Europe's total manufacturing outputs and resource requirements. Anticipating the difficulties associated with recruiting knowledgeable and experienced respondents, we employed convenience sampling to target managers with knowledge of their firm's SSCM practices and organisational performance (Malhotra and Grover, 1998). The questionnaire survey was administered using convenience sampling to a subset of the population of manufacturing managers, e.g., plant managers, logistics managers, operations managers, purchasing managers, supply chain managers, sales managers, engineering managers and industrial waste managers.

\subsection{Data collection}

The surveys were conducted via a Web-based survey service (Bristol Online Surveys) from March 2014 to April 2014 and data was collected from 146 qualified managers from various manufacturing firms. The data collection process was managed by Bristol Online Surveys and was structured so as to ensure unique responses from validated managers of UK manufacturers. The theorised model was assessed following a Structural Equation Modelling (SEM) method. Hair et al. (2010) suggested that sample sizes from 150 to 400 are generally suitable for SEM analysis, with sample size varying according to the complexity of the model and the number of parameters to be estimated. Hence, we targeted a sample size of 200 so we could safely reach the minimum threshold of 150 required for SEM analysis given the practical implications of data collection.

Although response rates vary, Nulty (2008) asserted that the average response rate to online surveys in social research is generally 33 per cent. With this in mind, we set the threshold of 
the participation requests to 600 , as this could potentially provide us with 200 responses $(600 *(33 / 100))$ which falls within the recommended range. A total of 600 managers were contacted via email, 36 were screened out as non-managers and 194 managers completed the survey. Of the 194 respondents, 48 selected the "other manager" category. Because of concerns related to a lack of knowledge of sustainable supply chain management practices and organisational performance, data from these 48 was not included in the dataset analysed. Finally, data from 146 manufacturing managers who have the necessary knowledge to fully complete the survey was included in the dataset that is subsequently analysed. The effective response rate, therefore, is 25 per cent (146/(600-36)).

All of the respondents hold management positions in manufacturing firms. The majority of respondents (43 per cent) are operations and supply chain managers. The respondents selected 11 different industry classifications representing a diverse array of manufacturing firms. They are experienced in their current positions, with an average of 6.85 years work experience. They work for firms with an average of 594.62 employees. According to the EU criteria, firms are classified as large ones if they have 250 employees or more and small/medium ones if they have fewer than 250 employees (Gimenez et al., 2012). We sought to target large manufacturing firms because they are likely to have undertaken some sustainable supply chain initiatives (Zhu et al., 2008). The sample is diverse as intended and is made up of individuals with knowledge of SSCM initiatives and organisational performance. Table 2 displays the sample demographics.

Table 2 Sample demographics summary

\begin{tabular}{lr}
\hline Title & Number \\
\hline Plant Manager & 16 \\
Logistics Manager & 19 \\
Operations Manager & 28 \\
Purchasing Manager & 13 \\
Supply Chain Manager & 36 \\
Sales Manager & 11 \\
Engineering Manager & 17 \\
Industrial Waste Manager & 6 \\
Total & 146 \\
Industry classification (UK SIC-Standard Industrial Classification) & \\
Manufacture of Food Products & 14 \\
Manufacture of Beverages & 6 \\
Manufacture of Wood and of Products of Wood and Cork & 5 \\
Manufacture of Paper and Paper Products & 8 \\
Manufacture of Chemicals and Chemical Products & 17 \\
Manufacture of Basic Metals & 12 \\
\hline
\end{tabular}




\begin{tabular}{lr}
\hline Manufacture of Electrical Equipment & 23 \\
Manufacture of Machinery and Equipment & 14 \\
Manufacture of Motor Vehicles, Trailers and Semi-Trailers & 42 \\
Manufacture of other Transport Equipment & 3 \\
Other Manufacturing & 2 \\
Total & 146 \\
Mean years in current position & 6.85 \\
Mean number of employees & 594.62 \\
\hline
\end{tabular}

\subsection{Common method bias}

We have considered that common method bias (CMB) might arise in our survey as a potential threat in survey research. To avoid the 'item characteristic' effect as one of the key causes for common method bias (Podsakoff et al., 2003) due to ambiguous items that can result in unreliable answers, we pretested the measurement items in the questionnaire survey by interviewing a number of plant-level manufacturing managers from the above-mentioned industrial sectors. We sought to determine whether the questionnaire items could be fully understood and if more items should be included to ensure that the questionnaire was practically capable of obtaining answers for the research inquiries. We made minor modifications based on interviewees' feedback, mainly on how to better present the measurement items in the questionnaire. Furthermore, as a result of these minor adjustments, a number of items that were overlapping were clarified to eliminate potential confusion.

Harman's one-factor test was also used as a post-hoc statistical test to examine the possibility of the CMB problem (Podsakoff and Organ, 1986). In this test, a principal component factor analysis was performed using Varimax rotation method with all research variables in the model. The results of the factor analysis revealed that four factors explain $73.16 \%$ of the variance of the variables with $26.44 \%$ by the first extracted factor. According to Podsakoff and Organ (1986) and Inman et al. (2010), substantial common method bias is signalled by the emergence of either a single factor or one "general" factor that explains a majority of the total variance.

\subsection{Non-response bias}

To test for non-response bias, the responses of early and late waves of returned surveys were compared, based on the assumption that the opinions of late respondents are representative of the opinions of the theoretical non-respondents (Rogelberg and Stanton, 2007). Respondents 
were categorised as responding to either the initial or follow-up requests that were sent approximately two weeks later. Of the respondents, 61 per cent (89) were categorised as early respondents and 39 per cent (57) were categorised as late respondents. A comparison of the means of the demographic variables and the summary variables for the two groups was conducted using one-way ANOVA. The comparisons resulted in statistically non-significant differences at the 0.01 level. Since non-respondents have been found to descriptively resemble late respondents (Lambert and Harrington, 1990; Green et al., 2012a), this finding of general equality between early and late respondents indicates that non-response bias has not impacted the data set, suggesting that non-response bias was not a problem.

\section{Analysis and results}

Because of our objective to assess the theorised model as a whole, we opted to assess the model using the Structural Equation Modelling (SEM) method. LISREL 8.80 software was used to perform both the confirmatory factor analysis necessary to assess the measurement model and the structural analysis necessary to assess the theorised model, because the software package can show the important model fit information.

\subsection{Scale assessment process}

The measurement scales were assessed for reliability and validity. Since all scales were taken directly from prior research (Zhu and Sarkis, 2006; Esty and Winston, 2009; Green et al., 2012b; Zhu et al., 2013), content validity was assumed. Following Gerbing and Anderson (1988), each pair of scales under consideration was tested for discriminant validity using a chi-square difference test. Chi-square difference tests for pairings of each scale with other scales returned significant differences at the 0.01 level, indicating sufficient discriminant validity for all scales (Garver and Mentzer, 1999; Gerbing and Anderson, 1988).

The construct validity of the theoretical constructs was also assessed using exploratory factor analysis (EFA) to "determine whether the majority of the variance can be accounted for by one general factor" (Podsakoff et al., 2003, p. 890). As a result of exploratory factor analysis, the "Sustainable Distribution" construct (SDIST6) and "Environmental Performance" construct (ENV6 and ENV7) measurement items were excluded (see Appendix A for details of the measurement scales). Consequently, all of the constructs yield an average factor loading of 0.84 , exceeding the recommended 0.70 level, providing evidence of self-reporting 
scales (Kline, 1994). This confirmed that all of the remaining measurement items in each construct represent one factor, indicating sufficient construct validity (Hair et al., 2010).

Furthermore, all standardised coefficients for scale items presented in Table 3 exceed the recommended 0.70 minimum and are significant at the 0.01 level, indicating sufficient convergent validity (Garver and Mentzer, 1999). All of the reliability coefficients (Cronbach alpha values) for all of the measurement scales exceed the recommended 0.70 level, indicating sufficient reliability (Garver and Mentzer, 1999). The standardised coefficients for measuring items and their associated t-values along with the Cronbach alpha values for all of the scales are displayed in Table 3.

\subsection{Measurement model assessment}

The measurement items were also assessed within the context of the full measurement model using confirmatory factor analysis (CFA), as recommended by Koufteros (1999). The results of the confirmatory factor analysis (CFA) are in Table 3. The measurement model fits the data well, with a relative chi-square (chi-square/degrees of freedom) value of 1.368, a root mean square error of approximation (RMSEA) value of 0.052, a comparative fit index (CFI) value of 0.981 , an incremental fit index (IFI) value of 0.988 , and a non-normed fit index (NNFI) value of 0.964 .

The relative chi-square value is less than the 3.00 maximum recommended by Kline (1998) and the RMSEA value is below the recommended maximum of 0.08 (Schumacker and Lomax, 2004). Byrne (1998) points out that the Comparative Fit Index (CFI) and Incremental Fit Index (IFI) are more appropriate when the sample size is small. The CFI (0.981) and IFI (0.988) both exceed the recommended 0.90 level (Byrne, 1998). The results relating to fit of the model generally support a claim of good fit. Furthermore, none of the standardised residuals exceeds the 4.00 maximum recommended by Hair et al. (2010), suggesting that there is no concern regarding a potential unacceptable degree of error. Table 3 displays the measurement model results along with the model fit indices. 
Table 3 Measurement model results

\begin{tabular}{|c|c|c|c|}
\hline Constructs & Alpha & Standardised Coefficient & t-values \\
\hline Coercive Pressures (CP) & 0.745 & & \\
\hline CP1 & & 0.90 & 14.33 \\
\hline $\mathrm{CP} 2$ & & 0.84 & 12.82 \\
\hline CP3 & & 0.82 & 12.26 \\
\hline $\mathrm{CP} 4$ & & 0.88 & 14.16 \\
\hline CP5 & & 0.92 & 14.94 \\
\hline CP6 & & 0.82 & 12.18 \\
\hline Sustainable Procurement (SP) & 0.816 & & \\
\hline SP1 & & 0.83 & 12.46 \\
\hline SP2 & & 0.85 & 13.24 \\
\hline SP3 & & 0.85 & 13.50 \\
\hline SP4 & & 0.79 & 11.39 \\
\hline SP5 & & 0.88 & 14.11 \\
\hline SP6 & & 0.89 & 14.25 \\
\hline Sustainable Distribution (SDIST) & 0.738 & & \\
\hline SDIST1 & & 0.82 & 12.41 \\
\hline SDIST2 & & 0.86 & 13.66 \\
\hline SDIST3 & & 0.86 & 13.58 \\
\hline SDIST4 & & 0.78 & 11.28 \\
\hline SDIST5 & & 0.80 & 11.62 \\
\hline Sustainable Design (SD) & 0.853 & & \\
\hline SD1 & & 0.90 & 14.69 \\
\hline SD2 & & 0.89 & 14.22 \\
\hline SD3 & & 0.86 & 13.77 \\
\hline SD4 & & 0.92 & 15.52 \\
\hline SD5 & & 0.88 & 14.13 \\
\hline SD6 & & 0.88 & 14.05 \\
\hline Investment Recovery (IR) & 0.705 & & \\
\hline IR1 & & 0.77 & 10.84 \\
\hline IR2 & & 0.78 & 11.08 \\
\hline IR3 & & 0.78 & 11.20 \\
\hline Environmental Performance (ENV) & 0.795 & & \\
\hline ENV1 & & 0.84 & 12.71 \\
\hline ENV2 & & 0.85 & 13.15 \\
\hline ENV3 & & 0.82 & 12.32 \\
\hline ENV4 & & 0.81 & 12.08 \\
\hline ENV5 & & 0.90 & 14.48 \\
\hline Economic Performance (ECN) & 0.788 & & \\
\hline ECP1 & & 0.87 & 13.93 \\
\hline ECP2 & & 0.82 & 12.33 \\
\hline ECP3 & & 0.91 & 15.06 \\
\hline ECP4 & & 0.88 & 14.19 \\
\hline ECP5 & & 0.81 & 11.89 \\
\hline \multicolumn{4}{|c|}{ Notes: Chi-Square Ratio $=1.368 ; \mathrm{RMSEA}=0.052 ; \mathrm{NFI}=0.95 ; \mathrm{NNFI}=0.96 ; \mathrm{CFI}=0.98 ; \mathrm{IFI}=0.98$} \\
\hline
\end{tabular}

\subsection{Structural equation modelling results}

Multicollinearity can be a threat for structural models, as it can distort the effects of an individual construct, leading to incorrect estimations of regression weights (Hair et al., 2010). 
As such, we tested for multicollinearity by calculating the variance inflation factors $\left(\mathrm{VIF}^{1}\right)$ for each regression coefficient before reporting hypothesis testing results. A threshold of a VIF value that is less than or equal to 10.0 is a commonly used criterion to determine the presence of multicollinearity (Hair et al., 2010). The VIF values range from 1.136 to 1.874, significantly below the recommended threshold of 10.0, hence suggesting that multicollinearity does not pose a problem to our model.

Summary values for the research variables were computed by averaging the items in the scales. Descriptive statistics are presented in Table 4. All variables are sufficiently normally distributed with skewness and kurtosis coefficients within the -2.00 and +2.00 range (Field, 2009). Furthermore, correlation coefficients are positive and significant at the 0.01 level for all variable pairings. The correlations are presented in Table 5.

Table 4 Descriptive statistics

\begin{tabular}{lrrrrrr}
\hline & Minimum & Maximum & Mean & Std. Deviation & \multicolumn{1}{c}{ Skewness } & \multicolumn{1}{c}{ Kurtosis } \\
\hline CP & 2.17 & 4.62 & 3.584 & 0.563 & 0.259 & 1.020 \\
SP & 1.88 & 4.42 & 3.015 & 0.418 & -0.183 & -1.168 \\
SD & 2.37 & 5.00 & 3.369 & 0.554 & -0.496 & -0.873 \\
SDIST & 2.10 & 4.75 & 3.128 & 0.425 & -0.385 & -1.119 \\
IR & 1.47 & 3.52 & 2.313 & 0.539 & -0.746 & 0.086 \\
ENV & 2.00 & 4.79 & 3.367 & 0.433 & 0.552 & 0.479 \\
ECP & 2.00 & 4.56 & 3.086 & 0.526 & 0.384 & -0.787 \\
\hline
\end{tabular}

Table 5 Correlation matrix

\begin{tabular}{cccccccc}
\hline & CP & SP & SDIST & SD & IR & ENV & ECP \\
\hline CP & 1 & & & & & & \\
SP & $0.672^{* *}$ & 1 & & & & & \\
SDIST & $0.588^{* *}$ & $0.536^{* *}$ & 1 & & & & \\
SD & $0.691^{* *}$ & $0.544^{* *}$ & $0.610^{* *}$ & 1 & & & \\
IR & $0.345^{* *}$ & $0.364^{* *}$ & $0.377^{* *}$ & $0.442^{* *}$ & 1 & & \\
ENV & $0.536^{* *}$ & $0.578^{* *}$ & $0.616^{* *}$ & $0.638^{* *}$ & $0.486^{* *}$ & 1 & \\
ECP & $0.484^{* *}$ & $0.604^{* *}$ & $0.593^{* *}$ & $0.615^{* *}$ & $0.407^{* *}$ & $0.619^{* *}$ & 1 \\
\hline
\end{tabular}

Notes: ** indicates significance at the 0.01 level; $\mathrm{CP}=$ Coercive Pressures; $\mathrm{SP}=$ Sustainable Procurement; SDIST=Sustainable Distribution; SD=Sustainable Design; IR=Investment Recovery; ENV=Environmental Performance; $\mathrm{ECP}=$ Economic Performance

\footnotetext{
${ }^{1}$ The variance inflation factor (VIF) quantifies the severity of multicollinearity in regression analyses and indicates the degree to which each predictor variable is explained by other predictor variables (Hair et al., 2010).
} 
The theorised model was assessed with the Structural Equation Modelling (SEM) technique. Fig. 2 illustrates the model with the SEM results specified in the LISREL 8.80 output.

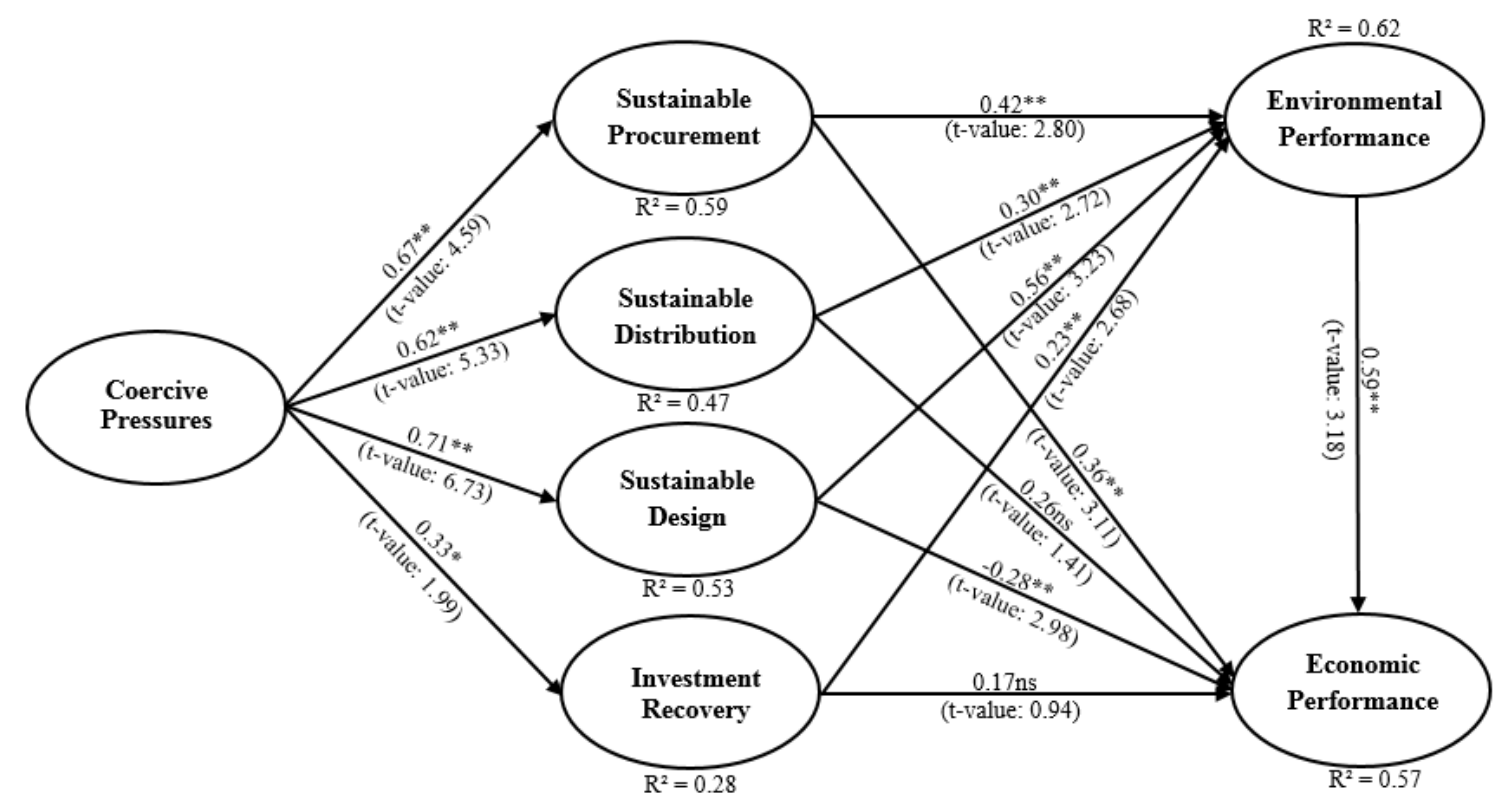

Notes: ** significant at the 0.01 level (t-value $>2.575$ ); * significant at the 0.05 level (t-value $>1.960)$; ns: not significant $(\mathrm{t}$-value $<1.960)$. Fit Indicators: Chi-Square ratio $=1.492 ; \mathrm{RMSEA}=0.059 ; \mathrm{NFI}=0.919 ; \mathrm{NNFI}=0.938 ; \mathrm{CFI}=0.970 ; \mathrm{IFI}=0.970$.

Fig. 2. SEM results on the antecedent and performance outcomes of implementing SSCM

The SEM results related to individual hypothesis tests are displayed in Table 6. All hypotheses are positive and significant with the exception of $H 3 b$ (SDIST $\rightarrow$ ECP), $H 3 c$ (SD $\rightarrow \mathrm{ECP}$ ), and $H 3 d$ (IR $\rightarrow \mathrm{ECP}$ ). Hla, Hlb, Hlc and Hld are positive and significant, indicating that coercive pressures are deemed to be powerful precursors that give rise to the implementation of SSCM practices. $H 2 a, H 2 b, H 2 c$ and $H 2 d$, which predict positive associations between SSCM practices and environmental performance, are positive and significant as expected. However, $H 3 a, H 3 b, H 3 c$ and $H 3 d$, which predict positive associations between SSCM practices and economic performance, have another version of story: the sustainable procurement to economic performance link is significant and positive; Sustainable distribution and investment recovery do not impact on economic performance; and sustainable design negatively impacts on economic performance. Lastly, $H 4$ is positive and significant as expected indicating that environmental performance positively impacts economic performance. It is worth noting that Zhu and Sarkis (2006) did not originally consider the relationship between environmental and economic performance. This paper advanced their work by developing an inter-linkage between these performance constructs. 
Table 6 Structural model results

\begin{tabular}{|c|c|c|}
\hline Model link & Standardised coefficient & Hypothesis tests results \\
\hline \multicolumn{3}{|c|}{ Hypothesis tests } \\
\hline \multicolumn{3}{|l|}{$\mathrm{CP} \longrightarrow$} \\
\hline SP & $0.67 * *$ & H1a: Supported \\
\hline SDIST & $0.62 * *$ & H1b: Supported \\
\hline SD & $0.71 * *$ & H1c: Supported \\
\hline IR & $0.33 *$ & H1d: Partially supported \\
\hline \multicolumn{3}{|l|}{$\mathrm{SP} \longrightarrow$} \\
\hline ENV & $0.42 * *$ & H2a: Supported \\
\hline ECP & $0.36 * *$ & H3a: Supported \\
\hline \multicolumn{3}{|c|}{ SDIST $\longrightarrow$} \\
\hline ENV & $0.30 * *$ & H2b: Supported \\
\hline $\mathrm{ECP}$ & $0.26 \mathrm{~ns}$ & H3b: Not supported \\
\hline \multicolumn{3}{|l|}{$\mathrm{SD} \longrightarrow$} \\
\hline ENV & $0.56 * *$ & H2c: Supported \\
\hline $\mathrm{ECP}$ & $-0.28 * *$ & H3c: Not supported \\
\hline \multicolumn{3}{|l|}{$\mathrm{IR} \longrightarrow$} \\
\hline ENV & $0.23 * *$ & H2d: Supported \\
\hline $\mathrm{ECP}$ & $0.17 \mathrm{~ns}$ & H3d: Not supported \\
\hline \multicolumn{3}{|l|}{$\mathrm{ENV} \longrightarrow$} \\
\hline $\mathrm{ECP}$ & $0.59 * *$ & H4: Supported \\
\hline \multicolumn{3}{|c|}{$\begin{array}{l}\text { Notes: * significant at the } 0.05 \text { level; } * * \text { significant at the level } 0.01 ; \text { ns: not significant; } \\
\text { Chi-Square ratio }=1.492 ; \mathrm{RMSEA}=0.059 ; \mathrm{NFI}=0.919 ; \mathrm{NNFI}=0.938 ; \mathrm{CFI}=0.970 ; \mathrm{IFI}=0.970 ; \\
\mathrm{CP}=\text { Coercive Pressures; SP = Sustainable Procurement; SDIST = Sustainable Distribution; SD = } \\
\text { Sustainable Design; IR = Investment Recovery; ENV = Environmental Performance; ECP = Economic } \\
\text { Performance. }\end{array}$} \\
\hline
\end{tabular}

Furthermore, in order to further examine the impact of firm size on relationships between embedded constructs, we tested if the results of the regression coefficients differ between large and medium/small firms. The results show that the coefficient for size is insignificant, hence indicating that the effects of the SSCM practices on performance outcomes are similar irrespective of the firm size.

\section{Discussion}

Whilst not all of the individual hypotheses are supported, the constructs stand together reasonably well, grounded on the good fit of the structural model and the statistical support for the majority of the hypotheses. We believe that our model is a good representation of the relationships among the constructs. The empirical results demonstrate a significant linkage between governance pressures, the implementation of SSCM practices and the environmental performance of manufacturing firms operating in the UK. However, the results related to the 
linkage between SSCM implementation driven by governance pressures and economic performance is less clear-cut. Overall, the results show that structural relationships between governance pressures, SSCM practices, environmental and economic performances exist, supporting further development of more proactive environmental practices within the context of supply chain management. They also support the merits of the idea that governance gives rise to the adoption of sustainable supply chain management which is capable of delivering environmental and ecological benefits.

\subsection{Governance pressures and SSCM practices}

This study shows that coercive pressures generally relate to UK manufacturers implementing SSCM practices including sustainable procurement, sustainable distribution, sustainable design and investment recovery. Coercive pressures directly impact all of the SSCM practices and indirectly impact firms' environmental and economic performances through these SSCM practices. Overall, coercive pressures are found to be major driving forces that lead manufacturers to pursue SSCM practices, indicating the critical role of governance in the adoption of an SSCM agenda.

The statistical results indicate that coercive pressures are most significantly associated with sustainable design, with standardised coefficients $\beta=0.71$ (sig. at the 0.01 level), followed by sustainable procurement $(\beta=0.67$, sig. at the 0.01 level $)$ and sustainable distribution $(\beta=$ 0.62 , sig. at the 0.01 level). This observation is consistent with the findings of previous studies (Zhu et al., 2013), and can be explained by the fact that most of the environmental impact on a product and its processes are 'locked' into the product at the design stage when materials are selected and product performance is largely determined, irrespective of where the product lies in the product life cycle (Lewis and Harvey, 2001). Therefore, environmental regulatory bodies mainly attempt to enact strict environmental regulations at the product design stage as the most effective measure to mitigate the product's negative environmental impact (Yu and Ramanathan, 2015).

Coercive pressures are also significantly and positively associated with sustainable procurement and sustainable distribution. During the past few years, the UK government, in order to improve sustainable distribution and better design of processes and logistics, has enacted stringent regional and national environmental regulations to limit the use of nonrenewable resources such as diesel and petrol ( $\mathrm{Yu}$ and Ramanathan, 2015). The UK 
government has also offered financial incentives such as grants and tax reductions to encourage manufacturers to embark upon using bio-fuels for their transportation systems (Taylor and Taylor, 2013). Furthermore, regional and national resource saving and conservation regulations and their associated compliance issues have led the UK manufacturers to pursue sustainable procurement, which allows the initiation of the development of environmentally friendly products or services. Coercive pressure is partially associated with investment recovery, with standardised coefficients $\beta=0.33$ (sig. at the 0.05 level), This can be explained by the fact that the practice of investment recovery is more external to a firm, making the firm have less control over the implementation of this practice (Zhu et al, 2012). Exogenous driving forces of governance may not greatly influence manufacturing firms to embark upon external SSCM practices. Such empirical results are generally consistent with the findings of previous studies (Zhu et al., 2007; Zhu et al., 2013).

Overall these findings suggest that exogenous pressures of governance cause manufacturing firms to embark upon SSCM implementation and should be in place before SSCM practices are expected to be adopted. In effect, the exogenous driving forces of governance are found to be necessary for the adoption of SSCM practices. Therefore, governance pressures are identified as necessary precursors to the implementation of SSCM practices: sustainable procurement, sustainable distribution, sustainable design and investment recovery.

\subsection{SSCM and performance outcomes}

As the model depicts (see Fig. 2), all of the SSCM practices are positively and significantly associated with environmental performance. This indicates that SSCM practices lead to improved environmental performance. These results are in line with the work of Zhu and Sarkis (2007), Lee et al. (2012) and Green et al. (2012a). Generally, SSCM practices are designed with a focus on minimising environmental impacts. Such environmental impact minimisation should have direct environmental results and lead to higher levels of environmental performance. However, the results about the impact of SSCM implementation on economic performance are less clear-cut. In particular we found that sustainable design is negatively related to economic performance.

The empirical results show that sustainable procurement positively and significantly impacts on both environmental and economic performance, with standardised coefficients $\beta=0.42$ (sig. at the 0.01 level) and $\beta=0.36$ (sig. at the 0.01 level), respectively. Generally, the 
practice of sustainable procurement is environmentally friendly in nature and facilitates the development of environmentally friendly products and services, decreasing the levels of wastes and emissions. From an economic standpoint, the responsibility for sustainable procurement may lie with the suppliers rather than the manufacturers. Thus it is less costly for manufacturers to implement than other SSCM practices (Sarkis et al., 2010; Hollos et al., 2012).

On the other hand, the practice of sustainable design positively impacts environmental performance $(\beta=0.56$, sig. at the 0.01 level), and negatively and significantly impacts economic performance $(\beta=-0.28$, sig. at the 0.01 level). These results are in line with the findings of Zhu and Sarkis (2007), Green et al. (2012a) and Zhu et al. (2013). According to Grote et al. (2007, p. 4100), the aim of sustainable design is to "reduce a product's environmental impacts without creating a negative trade-off with other design criteria, such as functionality and costs". It appears, then, that sustainable design has not fully accomplished this intended aim. We therefore suggest that the current sustainable design requires further development and improvement. Furthermore, another reason for this negative relationship between sustainable design and economic performance may lie with the fact that eco-design requires capital investment (Zhu et al., 2013). In addition, the capacity of sustainable design to reduce environmental pollutants is counterbalanced by the increases in the associated costs, perhaps related to materials purchases (Zhu et al., 2012; Green et al., 2012a).

Sustainable distribution directly impacts environmental performance but does not significantly impact economic performance. This can be explained by the fact that the practice of sustainable distribution focuses on decreasing the levels of environmental pollutants, which can directly enhance the environmental performance. From an economic perspective, the lack of appropriate green infrastructures hinders the benefits of sustainable distribution (e.g. profitability and sales performance). It also requires more supporting technologies for green distribution initiatives (Zhu et al., 2007). This necessitates further infrastructure investment in order to tackle the potential lack of green capabilities and green distribution characteristics. While Zhu and Sarkis (2007) do not find sustainable distribution to be significantly linked to either economic or environmental performance, a recent study by Green et al. (2012b) reports that sustainable distribution directly impacts on environmental performance, which is in line with our findings. This consolidates our findings, providing evidence of consensus within existing knowledge. 
Investment recovery also positively impacts on environmental performance but does not significantly impact on economic performance. This may be explained by the fact that the practice of investment recovery has received less attention in the UK ( $\mathrm{Yu}$ and Ramanathan, 2015). Interestingly, our finding about the relationship between investment recovery and environmental performance is opposite to that of Zhu and Sarkis (2007), where the authors reported that investment recovery is positively associated with economic performance but not significantly associated with environmental performance. The difference may be attributed to the different sample sizes, regions and segments. However, our finding is consistent with the findings of more recent work by Zhu et al. (2013) and Green et al. (2012a). Overall, the empirical findings suggest that the adoption of SSCM practices leads to higher levels of environmental performance, resulting in environmental improvements, but does not necessarily lead to improved economic performance, as only sustainable procurement has a positive impact on economic performance. This indicates that SSCM implementation driven by governance pressures increases environmental and ecological benefits and potentially has the capacity to enhance economic performance.

Lastly, the environmental performance construct positively impacts economic performance ( $\beta$ $=0.59$, sig. at the 0.01 level). The relationship among the performance constructs seems to make logical sense, as the economic performance construct reflects savings that result from improved environmental performance (Zhu and Sarkis, 2006). The impact of the implementation of SSCM practices on economic performance can be further explained through the linkage among environmental and economic performance. In view of this, the sustainable distribution, sustainable design, and investment recovery constructs that do not directly and positively impact economic performance, indirectly impact economic performance through environmental performance.

\section{Implications and conclusions}

The findings of this study effectively achieve the research aims, shedding some important light on the merits of governance within the sustainable supply chain management in terms of ecological benefits and performance improvements. The results of this study suggest a number of interesting insights concerning sustainable supply chain research. First, this paper theorises and assesses a comprehensive Governance Pressures $\rightarrow$ SSCM Practices $\rightarrow$ Performance Outcomes model using the Structural Equation Modelling (SEM) method to investigate whether exogenous pressures of governance exist in SSCM adoption 
and thereafter what this can deliver in terms of performance outcomes. It is our belief that one of the major contributions of this study lies in the comprehensive nature of the theorised model, as it is capable of assessing the merits of governance within a sustainable supply chain context, covering both ecological benefits and performance gains. Second, this research extends the literature on sustainable supply chain management by applying the insights of governance to bridge sustainable supply chain governance (SSCG). The contribution to SCM knowledge is to demonstrate the linkage between SSCM and SSCG by exhibiting the theoretical linkages between governance pressures, SSCM practices and commensurate performance outcomes.

This paper also makes a significant contribution to on-going research that relates sustainable practices along the supply chain to performance outcomes, through the inclusion of exogenous driving forces of governance as a major antecedent to the adoption of such environmental initiatives. Thus, this paper bridges the existing gap surrounding the lack of empirical evidence in understanding the relationships between governance pressures, SSCM practices and performance outcomes from a comprehensive perspective. Furthermore, adopting Structural Equation Modelling (SEM) technique over the traditional path analysis has enabled this study to obtain more credible results by taking into account the influential effects of governance exogenous forces in examining the relationships between SSCM practices and performance outcomes. The significance of our study can be further extended, as this is one of a few empirical studies that bridges the mixed views on SSCM performance implications, by reporting relatively conclusive results, reaching consensus on the recent findings conducted by various authors. Moreover, the methodological contribution of this research broadly lies in the capability of the employed data analysis technique, i.e. SEM analysis, to rigorously examine the impacts of the implementation of SSCM practices on performance outcomes while taking into account the influential effects of governance pressures as driving forces, generating more credible findings.

Generally, our analysis shows that structural relationships exist among governance pressures, SSCM practices, and performance outcomes. The results reveal that coercive pressures have a significant positive effect on SSCM practices, hence suggesting that governance pressures exist in the adoption of SSCM practices and are deemed necessary for the implementation of SSCM practices. These results indicate that the governance pressures for environmental protection have driven UK manufacturers to embark upon environmentally orientated organisational initiatives across the supply chain and implement SSCM practices. Therefore, 
we conclude that governance pressures are necessary precursors to the successful implementation of SSCM practices, and should be in place before these environmental initiatives are expected to be adopted. The empirical results further suggest that the implementation of SSCM driven by governance pressures leads to a higher level of environmental performance, while the economic performance is somewhat compromised. We find that SSCM practices positively affect the environmental performance of UK manufacturing firms, resulting in environmental improvements. However, we find evidence that the adoption of sustainable practices across the supply chain does not necessarily lead to improved economic performance, as only sustainable procurement positively affects economic performance.

Overall, the results of our research clarify the proposition that the role of governance in the adoption of SSCM practices is indeed environmentally necessary, but that its merits might not be being reaped in terms of short-term profitability. While the short-term benefits of governance within sustainable supply chain may not be evident, long-term benefits can be accrued. Governance plays a critical role in the transition to a more sustainable society and is capable of bringing not only ecological and environmental benefits but also economic benefits by supporting financial incentives in the form of subsidies or tax reductions to encourage environmental management. This promises to allow manufacturing firms to balance economic benefits with environmental protection and further ensures a 'win-win' opportunity for the supply chain partners, minimising potential trade-offs between environmental and economic performance.

The findings of our study are generally consistent with the majority of prior investigations, and where contradictory results exist, our findings stand with more recent studies reporting similar results. This consolidates our findings and diminishes any potential contradictory directions. Hence, we conclude that this paper has reported relatively conclusive results on the topic of governance within sustainable supply chains and its commensurate performance gains.

\subsection{Managerial implications}

This study provides practical implications for both practitioners in the manufacturing context and policy-makers. Manufacturers are given insights into how they can gain improved economic performance from implementing SSCM practices. For instance, manufacturers 
need to understand the structural relationships between governance arrangements and internal and external aspects of implementing SSCM and ensure the coordination of their respective activities to arrive at better environmental performance for economic gains to be achieved. Public policy-makers and regulators can further understand how to motivate manufacturers to embark upon SSCM adoption. In particular, coercive forces are influential antecedents affecting the implementation of environmental initiatives in manufacturing. It is useful for the government and related bodies to promote SSCM by creating awareness of the benefits and sharing successful experiences. Such promotion can help to lessen firms' doubts about adopting SSCM and reduce the perception of the risks associated with the adoption of environmental innovations. This study informs policy-makers and regulators that effective governance arrangements in the supply chain along with financial incentives can provide 'win-win' opportunities for both environmental performance and economic benefits in implementing SSCM practices.

Furthermore, practitioners are provided with a validated framework for assessing the synergistic impact of SSCM practices on environmental and economic performances. In addition, the SSCM initiatives validated in this work can help manufacturing firms operating in both developed countries and emerging economies to identify those areas of SSCM that require improvement and the prioritisation of their green efforts. This work can be useful for manufacturing industries that need to convert their traditional supply chains into sustainable supply chains. In the resource-constrained environment of the EU, our framework points to the key environmental initiatives in the supply chain which need to be implemented, i.e. sustainable procurement, sustainable design, sustainable distribution and investment recovery. Collectively, the key SSCM initiatives can serve as an audit tool and later on as a benchmarking tool for managers to evaluate the perceptions of SSCM in their organisations. Policy-makers need to invest more in appropriate infrastructures that enhance green capabilities and expertise. This will also facilitate the benefits of SSCM practices being reaped in terms of long-term profitability and sales performance.

\subsection{Limitations and future directions}

As with any research, this study has some limitations that provide opportunities and directions for further research. First, we acknowledge that customer and competitor pressures were excluded in developing our research model. Future research may consider other antecedents to the implementation of SSCM practices such as customer and competitor 
pressures as motivating forces for sustainability adoption. Furthermore, internal support at senior management level is also found to be a key precursor to the implementation of environmental management practices (Carter et al., 1998). Future studies may carry out a comparative analysis between exogenous driving forces and endogenous factors that drive SSCM adoption, so that a more holistic view can be achieved. Second, research on SSCM is still at the early stage in developing appropriate measures of SSCM related organisational performance, particularly for economic performance (Tseng et al., 2015). This study has only measured economic performance in terms of reduced cost and could have further considered other quantifiable measurement criteria of economic performance such as increased profits, growth, brand image and so forth. Future research may use and validate other economic measures than reduced costs to avoid limiting the economic performance dimension to cost performance through integration of other measures of supply chain performance (He et al., 2013). Third, we further recommend longitudinal studies to determine whether long-term economic performance is enhanced by implementing SSCM practices. Fourth, this study did not consider the aspects of organisational culture interaction between key customers and suppliers in the sustainable supply chain context, which can provide future research opportunities.

Moreover, future studies may examine other developed markets to eliminate the potential effect of country-level variance such as market size, economic development and legal systems. To increase the generalisability of the research, repeating this study for comparative analysis in different developed countries would be another research direction. In addition, future research can examine emerging economies such as China, the world's largest manufacturing country, and compare the findings with developed markets. Lastly, this research has been developed primarily with a focus on manufacturing firms, without consideration of other sectors such as the service sector and servitisation. Therefore, future studies may examine the applicability of our model to these sectors. 


\section{Appendix}

Table A1 Measurement scales

Coercive Pressures (Zhu et al., 2013)

Please indicate the importance of each of the following on SSCM practices adoption.

(five-point scale: 1 =unimportant, 2=somewhat unimportant, $3=$ =neutral, 4=somewhat important, and 5=very important)

CP1 National environmental regulations (such as waste emissions, cleaner production etc.).

CP2 National resource saving and conservation regulations.

CP3 Regional environmental regulations (such as waste emission, cleaner production etc.)

CP4 Regional resource saving and conservation regulations.

CP5 Export countries' environmental regulations.

CP6 Products potentially conflict with laws (such as circular economy, EPR, EHS etc.).

Sustainable Procurement (Zhu and Sarkis, 2006)

Please indicate the extent to which you perceive that your company is implementing each of the following.

(five-point scale: 1 = no implementation; 2 = planning to consider implementation; 3 = currently considering implementation; 4 = initiating implementation; 5 = implementing fully)

SP1 Eco labelling of products.

SP2 Cooperation with suppliers for environmental objectives.

SP3 Environmental audit for suppliers' internal management.

SP4 Suppliers' ISO 14000 certification.

SP5 Second-tier supplier environmentally friendly practice evaluation.

SP6 Providing design specification to suppliers that include environmental requirements for purchased item.

Sustainable Distribution (Zhu and Sarkis, 2006; Green et al., 2012b)

Please indicate the extent to which you perceive that your company is implementing each of the following.

(five-point scale: 1 = no implementation; 2 = planning to consider implementation; 3 = currently considering implementation; 4 = initiating implementation; 5 = implementing fully)

SDIST1 Cooperation with customers for using less energy during product transportation.

SDIST2 Cooperation with customers for green packaging.

SDIST3 Use of renewable energy in any mode of products transportation.

SDIST4 Use of renewable energy in the process of products packaging.

SDIST5 Upgrade freight logistics and transportation systems (either software or hardware such as minimising empty miles, reducing container weight, improving refrigeration, etc.).

SDIST6 Tracking and monitoring emissions caused in products distributions (e.g., carbon footprint).

Sustainable Design (Zhu and Sarkis, 2006; Esty and Winston, 2009)

Please indicate the extent to which you perceive that your company is implementing each of the following.

(five-point scale: 1 = no implementation; 2 = planning to consider implementation; 3 = currently considering implementation; 4 = initiating implementation; 5 = implementing fully)

SD1 Design of products for reduced consumption of material.

SD2 Design of products for reduced consumption of energy.

SD3 Design of products for reuse, recycle, recovery of material, component parts, and by-products.

SD4 Design of products to avoid or reduce use of hazardous materials in their manufacturing process.

SD5 Cooperation with customers for eco design.

SD6 Cooperation with customers for cleaner production.

Investment Recovery (Zhu and Sarkis, 2006)

Please indicate the extent to which you perceive that your company is implementing each of the following. 
(five-point scale: 1 = no implementation; 2 = planning to consider implementation; 3 = currently considering implementation; 4 = initiating implementation; 5 = implementing fully)

IR1 Sale of excess inventories or materials.

IR2 Sale of scrap and used materials or by-products.

IR3 Sale of excess capital equipment.

Environmental Performance (Zhu and Sarkis, 2006)

Please indicate the extent to which you perceive that your company has achieved each of the following during the past year.

(five-point scale: $1=$ not at all; $2=$ a little bit; $3=$ to some degree; $4=$ relatively significant; $5=$ significant)

ENV1 Reduction of air emission.

ENV2 Reduction of waste emission.

ENV3 Reduction of solid wastes.

ENV4 Reduction of effluent wastes.

ENV5 Decrease of consumption for hazardous/harmful/toxic materials.

ENV6 Decrease of frequency for environmental accidents.

ENV7 Improvement of an enterprise's environmental situation.

Economic Performance (Zhu and Sarkis, 2006)

Please indicate the extent to which you perceive that your company has achieved each of the following during the past year.

(five-point scale: $1=$ not at all; $2=$ a little bit; 3 = to some degree; $4=$ relatively significant; $5=$ significant)

ECP1 Decrease of cost for purchased materials.

ECP2 Decrease of cost for energy consumption.

ECP3 Decrease of fee for waste treatment.

ECP4 Decrease of fee for waste discharge.

ECP5 Decrease of fine for environmental accidents.

Table A1. Measurement scales

\section{Reference}

Beamon, B.M., 1999. Designing the green supply chain. Logistics Information Management. 12 (4), 332-342.

Boström, M., Jönsson, A.M., Lockie, S., Mol, A., Oosterveer, P., 2015. Sustainable and responsible supply chain governance: challenges and opportunities. Journal of Cleaner Production. 107 (16), 1-7.

Bowen, F.E., Cousins, P.D., Lamming, R.C., Faruk, A.C., 2001. The role of supply management capabilities in green supply. Production and Operations Management. 10 (2), 174-189.

Byrne, B.M., 1998. Structural Equation Modeling with LISREL, PRELIS, and SIMPLIS. Lawrence Erlbaum Associates, Mahwah, NJ.

Carter, C.R., Ellram, L.M., Ready, J., 1998. Environmental purchasing: benchmarking our German counterparts. International Journal of Purchasing and Materials Management. 34 (4), $28-38$

Carter, R.C., Carter, J.R., 1998. Interorganizational determinants of environmental purchasing: initial evidence from the consumer products industry. Decision Sciences. 29 (3), 28-38. 
de Bakker, F., Fisscher, O., Brack, A., 2002. Organizing product-oriented environmental management from a firm's perspective. Journal of Cleaner Production. 10 (5), 455-464.

DiMaggio, P.J., Powell, W.W., 1983. The iron cage revisited: Institutional isomorphism and collective rationality in organizational fields. American Sociological Review. 48, 147-160.

Esty, D.C., Winston, A.S., 2009. Green to Gold: How Smart Companies Use Environmental Strategy to Innovate, Create Value, and Build a Competitive Advantage, revised and updated ed. Wiley, Chichester and Hoboken, NJ.

Field, A., 2009. Discovering Statistics Using SPSS. Third Edition, SAGE Publications Ltd.

Garver, M.S., Mentzer, J.T., 1999. Logistics research methods: employing structural equation modeling to test for construct validity. Journal of Business Logistics, 20 (1), 33-57.

Geffen, C., Rothenberg, S., 2000. Suppliers and environmental innovation: the automotive paint process. International Journal of Operations \& Production Management, 20 (2), 166-86.

Gerbing, D.W., Anderson, J.C., 1988. An updated paradigm for scale development incorporating unidimensionality and its assessment. Journal of Marketing Research, 25 (2), 186-192.

Gerrard, J., Kandlikar, M., 2007. Is European end-of-life vehicle legislation living up to expectations? Assessing the impact of the ELV Directive on 'green' innovation and vehicle recovery. Journal of Cleaner Production. 15 (1), 17-27.

Gimenez, C., Sierra, V., Rodon, J., 2012. Sustainable Operations: Their Impact on the Triple Bottom Line. International Journal of Production Economics. 140 (1). 149-159.

Green, K.W., Toms, L.C., Clark, J., 2015. Impact of market orientation on environmental sustainability strategy. Management Research Review. 38(2), 217-238.

Green, K.W., Zelbst, P.J., Bhadauria, V.S., Meacham, J., 2012b. Do environmental collaboration and monitoring enhance organizational performance? Industrial Management \& Data Systems, 112 (2), 186-205.

Green, K.W., Zelbst, P.J., Meacham, J., Bhadauria, V.S., 2012a. Green supply chain management practices:impact on performance. Supply Chain Management: An International Journal. 17 (3), 290-305.

Grote, C., Jones, R., Blount, G., Goodyer, J.J., Shayler, M.M., 2007. An approach to the EuP Directive and the application of the economic eco-design for complex products. International Journal of Production Research. 45 (18/19), 4099-4117.

Hair, J.F., Anderson, R.E., Tatham, R.L., Black, W.C., 2010. Multivariate Data Analysis, Seventh ed. Prentice-Hall, New Jersey.

He, Q., Ghobadian, A., Gallear, D., 2013. Knowledge Acquisition in Supply Chain Partnerships: The Role of Power. International Journal of Production Economics. 141 (2), 605-618. 
Hollos, D., Blome C., Foerstl, K., 2012. Does sustainable supplier cooperation affect performance? Examining implications for the triple bottom line. International Journal of Production Research. 50(11), 2968-2986.

Hsu, W., Hu, H., 2009. Applying hazardous substance management to supplier selection using analytic network process. Journal of Cleaner Production. 17, 255-264.

Inman, A., Sale, S., Green, K.W., Whitten, D., 2011. Agile manufacturing: Relation to JIT, operational performance and firm performance. Journal of Operations Management. 29 (4), 343-355.

Jolink, A., Niesten, E., 2015. Sustainable development and business models of entrepreneurs in the organic food industry. Business Strategy and the Environment. 24, 386-401

Kline, R.B., 1998. Principles and Practice of Structural Equation Modeling. Guilford Press, New York, NY.

Koh, S.C.L., 2012. Cross-tier ripple and indirect effects of directives WEEE and RoHS on greening a supply chain. International Journal of Production Economics. 140 (1), 305-317.

Koufteros, X.A., 1999. Testing a model of pull production: a paradigm for manufacturing research using structural equation modelling. Journal of Operations Management. 17 (4), 467-488.

Lai, K.H., Lun, Y.H.V., Wong, C.W.Y., Cheng, T.C.E., 2011. Green shipping practices in the shipping industry: conceptualization, adoption, and implications. Resources Conservation and Recycling. 55 (6), 631-638.

Lambert, D.M., Harrington, T.C., 1990. Measuring nonresponse bias in customer service mail surveys. Journal of Business Logistics. 11 (2), 5-25.

Lee, S.M., Kim, S.T., Choi, D., 2012. Green supply chain management and organizational performance. Industrial Management \& Data Systems. 112, 1148-1180.

Levy, D.L., 1995. Heterogeneity and change in environmental strategy: technological and political responses to climate change in the global automobile industry. in Hoffman, A. J. and Ventresca, M.J. (Eds), Organizations, Policy and the Natural Environment: Institutional and Strategic Perspectives, Stanford University Press, Stanford. 173-193.

Lewis, G.J., Harvey, B., 2001. Perceived environmental uncertainty: the extension of Miller's scale to the natural environment. Journal of Management Studies. 38 (2), 201-233.

Lin, C.Y., Ho, Y.H., 2011. Determinants of green practice adoption for logistics companies in China. Journal of Business Ethics. 98 (1), 67-83.

Linton, D., Klassen, R., Jayaraman, V., 2007. Sustainable supply chains: an introduction. Journal of Operations Management. 25, 1075-1082.

Lozano, R., 2008. Developing collaborative and sustainable organisations. Journal of Cleaner Production. 16, 499-509. 
Lozano, R., Carpenter, A., Huisingh, D., 2015. A review of 'theories of the firm' and their contributions to corporate sustainability. Journal of Cleaner Production. 106, 430-442.

Malhotra, M. K., Grover, V., 1998. An assessment of survey research in POM: from constructs to theory. Journal of Operations Management. 16 (4), 407-425.

Niesten, E., Jolink A., 2014. Absence of a market in the Dutch balancing mechanism: European rules versus specific investments. European Journal of Law and Economics. 38 (1), 71-90.

Nulty, D.D., 2008. The adequacy of response rates to online and paper surveys: what can be done. Assessment \& Evaluation in Higher Education. 33 (3), 301-314.

Podsakoff, P.M., MacKenzie, S.B., Lee, J.Y., Podsakoff, N.P., 2003. Common Method Biases in Behavioral Research: A Critical Review of the Literature and Recommended Remedies. Journal of Applied Psychology. 88 (5), 879-903.

Podsakoff, P.M., Organ, D.M., 1986. Self-reports in organizational research: Problems and prospects. Journal of Management, 12 (4), 531-544.

Porter M.E., Van der Linde, C., 1995. Toward a New Conception of the EnvironmentCompetitiveness Relationship. Journal of Economic Perspectives, 97-118.

Rao, P., 2005. The greening of suppliers - in the South East Asian context", Journal of Cleaner Production, 13 (9), 935-945.

Rao, P., Holt, D., 2005. Do green supply chains lead to competitiveness and economic performance?. International Journal of Operations \& Production Management. 25 (9/10), 898-916.

Rivera, J., 2004. Institutional pressures and voluntary environmental behavior in developing countries: Evidence from the Costa Rican hotel industry. Society \& Natural Resources. 17 (9), 779-797.

Rogelberg, S.G., Stanton, J.M., 2007. Understanding and dealing with organizational survey nonresponse. Organizational Research Methods. 10, 195-209.

Sarkis, J., 2011. An organizational theoretic review of green supply chain management literature. International Journal of Production Economics. 130 (1), 1-15.

Sarkis, J., Gonzalez-Torre, P., Adenso-Diaz, B., 2010. Stakeholder Pressure and the Adoption of Environmental Practices: The Mediating Effect of Training. Journal of Operations Management. 28, 163-176.

Schumacker, R.E., Lomax, R.G., 2004. A Beginner's Guide to Structural Equation Modeling. Lawrence Erlbaum Associates, Mahwah, NJ.

Seuring, S., Müller, M., 2008a. From a literature review to a conceptual framework for sustainable supply chain management. Journal of Cleaner Production. 16 (15), 1699-1710.

Seuring, S., Müller, M., 2008b. Core issues in sustainable supply chain management - A Delphi study. Business Strategy and the Environment. 17(8), 455-466. 
Seuring, S., Sarkis, J., Müller, M., Rao, P., 2008. Sustainability and supply chain management. Journal of Cleaner Production. 16 (15), 1545-1710.

Su, C.M., Horng, D.J., Tseng, M.L., Chiu, A.S.F., Wu, K.J., Chen, H.P., 2015. Improving sustainable supply chain management using a novel hierarchical grey-DEMATEL approach. Journal of Cleaner Production. 1-13.

Taylor, A., Taylor, M., 2013. Antecedents of effective performance measurement system implementation: an empirical study of UK manufacturing firms. International Journal of Production Research, 51 (18), 5485-5498.

Tseng, M. L., Lim. M., Wong, W.P., 2015. Sustainable supply chain management. Industrial Management \& Data Systems. 115 (3), 436-461.

Tsoulfas, G.T., Pappis, C.P., 2006. Environmental principles applicable to supply chains design and operation. Journal of Cleaner Production. 14 (18), 1593-1602.

Vachon, S., Klassen, R. D., 2006b. Extending green practices across the supply chain. International Journal of Operations and Production Management, 26 (7), 795-821.

Vachon, S., Klassen, R., 2006a. Green project partnership in the supply chain: the case of the package printing industry. Journal of Cleaner Production. 14, 661-671.

Vezzoli, C., Ceschin, F., Diehl, J.C., Kohtala, C., 2012. Why have 'Sustainable ProductService Systems' not been widely implemented? Meeting new design challenges to achieve societal sustainability. Journal of Cleaner Production, 35, 288-290.

Vurro, C., Russo, A., Perrini F., 2009. Shaping sustainable value chains: Network determinants of supply chain governance models. Journal of Business Ethics. 90, 607-621.

Yu, W., Ramanathan, R. 2015. An empirical examination of stakeholder pressures, green operations practices and environmental performance. International Journal of Production Research. 53 (21), 6390-6407.

Zailani, S.H.M., Eltayeb, T.K., Hsu, C.C., Tan, K.C., 2012. The impact of external institutional drivers and internal strategy on environmental performance. International Journal of Operations \& Production Management. 32 (6), 721-745.

Zhu, O., Sarkis, J., Geng, Y., 2005. Green supply chain management in china: pressures, practices and performance. International Journal of Operations \& Production Management. 25 (5), 449-468.

Zhu, Q., Hashimoto, S., Fujita, T., Geng, Y., 2010. Green supply chain management in leading manufacturers: Case studies in Japanese large companies. Management Research Review. 33 (4), 380-392.

Zhu, Q., Sarkis, J., 2004. Relationships between operational practices and performance among early adopters of green supply chain management practices in Chinese manufacturing enterprises. Journal of Operations Management. 22 (3), 265-289. 
Zhu, Q., Sarkis, J., 2006. An inter-sectoral comparison of green supply chain management in China: drivers and practices. Journal of Cleaner Production. 14, 472-486.

Zhu, Q., Sarkis, J., 2007. The moderating effects of institutional pressures on emergent green supply chain practices and performance. International Journal of Production Research. 45 (18/19), 4333-4355.

Zhu, Q., Sarkis, j., Lai, K., 2007. Green supply chain management: pressures, practices and performance within the Chinese automobile industry. Journal of Cleaner Production. 15 (11/12), 1041-1052.

Zhu, Q., Sarkis, J., Lai, K., 2012. Examining the effects of green supply chain management practices and their mediations on performance improvements. International Journal of Production Research. 50 (5), 1377-1394.

Zhu, Q., Sarkis, J., Lai, K., 2013. Institutional-based antecedents and performance outcomes of internal and external green supply chain management practices. Journal of Purchasing \& Supply Management. 19. 106-117.

Zhu, Q., Sarkis, J., Lai, K., Geng, Y., 2008. The role of organizational size in the adoption of green supply chain management practices in China. Corporate Social Responsibility and Environmental Management. 15 (6), 322-337. 